\title{
Socialização Parental e Valores: Um Estudo com Adolescentes
}

\author{
Parental Socialization and Values: A Study with Teenagers
}

\author{
Raquel Moraes*a ${ }^{*}$, Cleonice Camino ${ }^{\mathrm{b}}$, Joselí B. da Costa ${ }^{\mathrm{b}}$, Leoncio Camino ${ }^{\mathrm{b}} \&$ Luciane Cruz $^{\mathrm{c}}$ \\ ${ }^{\text {a } U n i v e r s i d a d e ~ E s t a d u a l ~ d a ~ P a r a i ́ b a, ~ G u a r a b i r a ~ B r a s i l, ~}{ }^{\mathbf{b}}$ Universidade Federal da Paraíba, João Pessoa, Brasil, \\ ${ }^{\mathrm{c}}$ UNIPÊ/Centro Universitário de João Pessoa, João Pessoa, Brasil
}

\begin{abstract}
Resumo
Este estudo buscou analisar as relações existentes entre a percepção das práticas parentais de socialização e os valores de adolescentes. Foram contatados 2.004 adolescentes, com idades entre 10 e 18 anos, de ambos os sexos, estudantes de escolas públicas e privadas, que responderam à Escala de Socialização Parental na Adolescência e ao Questionário de Valores Psicossociais. Em relação às práticas de socialização, os resultados demonstram que, ao contrário do esperado, a percepção dos adolescentes está organizada em três dimensões: aceitação, coerção e displicência. Os valores estão estruturados em quatro sistemas: materialista, pósmaterialista, hedonista e religioso. Foram encontradas relações, tanto positivas como negativas, entre as práticas parentais de socialização e os valores de adolescentes, o que permite supor que a socialização no contexto familiar reflete no processo de construção de valores dos adolescentes.

Palavras-chave: Práticas parentais de socialização; valores; adolescentes.
\end{abstract}

\begin{abstract}
This study investigates the relations between the perception of parental practices of socialization and the teenager's values. Two thousand and four (2.004) teenagers of both sexes, from public and private schools aged between 10 and 18 were contacted. Two questionnaires were used: the Teenage Parental Socialization Scale and the Questionnaire of Psychosocial Values. The results reveal that the teenagers' perceptions of parental socialization are organized in three dimensions: Acceptance, Control and Carelessness. They also show that the values are organized in four systems: Materialist, Post-materialist, Hedonic and Religious. Positive and negative relations were found among parental socialization practices and the teenager's values, which allow us to suppose that socialization in a family context reflects in the process of constructing the values of teenagers.

Keywords: Parental practices of socialization; values; teenagers.
\end{abstract}

Na tentativa de buscar uma solução para as questões sociais, algumas culturas ocidentais têm apontado para a necessidade de se voltar para a família enquanto arena de construção de valores. Isso se deve à suposição de que fatores relacionados à família de hoje, como pais solteiros e falta de controle parental, são fortemente responsáveis por problemas associados à juventude atual e, conseqüentemente, aos valores que esses jovens possuem (Shucksmith, Hendry \& Glendinning, 1995).

A focalização no papel da família está pautada, principalmente, no fato de que os pais são socialmente designados como primeiros responsáveis pela socialização (Kuczynski \& Grusec, 1997), uma vez que, por mais que as normas e os processos de socialização variem segundo os diversos contextos sociais, econômicos e políticos, o papel dos pais continua sendo o de avaliar se os comportamentos dos filhos são ou não adequados a estas normas sociais (Darling \& Steinberg, 1993). Sendo assim, dentre os contextos em que os adolescentes se desenvolvem, nenhum tem recebido tanta atenção como a família (Steinberg \& Morris, 2001). Ademais, como sustentam Assmar, Ferreira, Novaes e Tomaz (2000), com base em estudos empíricos, a família

* Endereço para correspondência: Av. Esperança, 1360/701, Manaíra, João Pessoa, PB, 58038-281. E-mail: raquelmoraes@superig.com.br reflete as normas, crenças e tradições de uma cultura, constituindo-se, desta forma, um contex to adequado a uma investigação das premissas históricas e sócio-culturais, que constituem crenças inquestionáveis consensualmente aceitas por um grupo social. A família, portanto, deve ser vista como uma esfera de formação social onde os valores são constantemente construídos, fragmentados e reconstruídos (Ribeiro \& Ribeiro, 1994), a partir da convivência familiar entre seus membros (Eisenberg \& Mussen, 1989).

Dentre os diferentes fatores que, no ambiente familiar, contribuem para a socialização dos filhos, focaliza-se, neste trabalho, o controle parental - o que os pais fazem para que seus filhos se comportem de forma socialmente desejável ou para evitar que se comportem de forma socialmente indesejável (para uma revisão, ver Maccoby, 1994).

A eficácia do controle parental depende da técnica ou método adotado pelos pais na tentativa de socializar os filhos. Isto porque as técnicas atuam de forma diferente no processo de internalização/interiorização. Observe-se que, mesmo divergindo na concepção do que seja internalização, a compreensão de que as técnicas atuam no processo de internalização é partilhada por diferentes teóricos (Aronfreed, 1976; Grusec, 2002; Grusec \& Goodnow, 1994; Hoffman, 1970; Piaget, 1932). 
Embora não se pretenda estudar a internalização - concebida no presente trabalho como um processo através do qual a sociedade externa se transforma em realidade subjetiva, a partir do momento em que, por meio da socialização, as pessoas dão significado à realidade em que vivem (Alvaro \& Garrido, 2003) -, parte-se do pressuposto de que ela é importante na formação dos valores. E, se as técnicas de socialização desempenham um papel relevante na internalização, os valores considerados importantes pelos filhos devem apresentar alguma relação com as técnicas ou práticas de socialização utilizadas pelos pais.

O estudo das técnicas de controle parental tem dado lugar, cada vez mais, ao estudo dos estilos de socialização. Compreende-se estilo de socialização por um conjunto de técnicas e formas de atuação que abrangem desde atitudes de aceitação até atitudes de controle dos comportamentos indesejados e imposição de limites aos filhos. Os estilos podem ser definidos pela persistência de certos padrões de atuação (Musitu \& García, 2001) e representam uma espécie de classificação do "clima" gerado na relação entre pais e filhos (Darling \& Steinberg, 1993).

O estilo não é apenas um conjunto de técnicas de socialização. Na verdade, o estilo inclui, além de técnicas, uma série de atitudes dos pais, que, por sua vez, dependem dos comportamentos dos filhos e do próprio contex to onde se realiza a socialização. Esse contexto varia de acordo com as crenças, as normas e os valores cultural e socialmente compartilhados.

Nos últimos anos, diversos trabalhos (Dornbusch, Ritter, Leiderman, Roberts \& Fraleigh, 1987; Lamborn, Mounts, Steinberg \& Dornbusch, 1991; Maccoby \& Martin, 1983; Steinberg, Lamborn, Darling, Mounts \& Dornbusch, 1994, dentre outros) têm se centrado nos estilos parentais para estudar o papel dos pais na educação de seus filhos. Esses estudos, de forma geral, têm demostrado a influência dos estilos parentais no comportamento social de crianças (Eisenberg \& Mussen, 1989) e em diversas áreas do desenvolvimento psicossocial dos adolescentes.

Em seu trabalho pioneiro sobre os estilos parentais, Baumrind (1971) integrou aspectos comportamentais e afetivos ao estudo da criação dos filhos (Camino, Camino \& Moraes, 2003; Costa, Teixeira \& Gomes, 2000). Essa autora propôs, inicialmente, a existência de três estilos ou formas de atuação: autoritativo ${ }^{1}$ (estilo caracterizado pelo controle e exigência dos pais, mas acompanhado de empatia, compreensão e comunicação com os filhos); autoritário (caracterizado pela distância entre pais e filhos, punição e pouca empatia) e permissivo (estilo que envolve pouca exigência e praticamente nenhuma punição, mas carinho, empatia e afetividade). Posteriormente, Baumrind $(1991,1996)$ acrescentou a esse modelo o estilo negligente (caracterizado, principalmente, pela falta de interesse dos pais pelos seus filhos).

O modelo de Baumrind $(1971,1991)$ foi bastante usado para investigar os fatores e as consequiências que envolvem

\footnotetext{
Embora a palavra autoritativo não exista em português, essa expressão foi escolhida - assim como fizeram Costa et al. (2000) - como tradução para o vocábulo inglês authoritative por guardar maior semelhança com o termo original.
}

a socialização familiar durante a infância. Mais recentemente, diversos estudos (Dornbusch et al., 1987; Lamborn et al., 1991; Steinberg et al., 1994) têm aplicado esse mesmo modelo para explicar variações nos padrões de desenvolvimento de adolescentes (Steinberg \& Morris, 2001).

Os estilos, conforme indica Baumrind (1971) e, posteriormente, Maccoby e Martin (1983), são caracterizados em função de duas dimensões: responsividade (responsiveness) $\mathrm{e}$ exigência (demandingness). A primeira refere-se a atitudes parentais de aceitação e aprovação do filho, através de comportamentos de apoio, afeição e encorajamento; a segunda inclui as atitudes dos pais que envolvem o controle do comportamento dos filhos e a imposição de limites e regras (Costa et al., 2000).

Partindo da suposição de que essas duas dimensões são independentes (no sentido de que se referem a práticas parentais diferenciadas), pode-se caracterizar, a partir delas, quatro tipos de estilos parentais: o autoritativo, caracterizado por ser alto em responsividade e exigência; o permissivo, caracterizado por ser alto em responsividade e baixo em exigência; o autoritário, com baixa responsividade e alta exigência e o negligente, com baixa responsividade e exigência (Steinberg et al., 1994).

Semelhantemente aos autores já citados, o modelo teórico de Musitu e García (2001), que fundamenta o corrente trabalho, parte do pressuposto básico de que a socialização parental está caracterizada por diferentes estilos de socialização, também definidos a partir de um modelo bidimensional, composto por dois eixos fundamentais:

'Aceitação': os pais que usam da aceitação expressam reações de aprovação, afeto e carinho quando seus filhos se comportam de acordo com as normas sociais. Além disso, se os filhos se comportam em desacordo com as normas, os pais utilizam o diálogo, pedem explicações aos filhos e expõem qual a forma correta de se comportar. Essa forma de atuação parental pode ocorrer tanto em situações que estão de acordo com a norma como em situações de desacordo, relacionando-se positivamente com as demonstrações parentais de afeto e carinho e negativamente com a indiferença, quando o filho se comportar de maneira adequada. Por sua vez, quando o filho violar as normas, essa atuação estará relacionada positivamente com o diálogo e negativamente com a displicência ou indiferença.

'Coerção': quando os comportamentos dos filhos são inadequados, os pais podem atuar de forma coercitiva, reprimindo tais comportamentos, utilizando, conjunta ou independentemente, a privação, a coerção verbal e a coerção física. Esta forma de atuação, que pode vir acompanhada ou não do diálogo, ocorre apenas quando os comportamentos dos filhos são discrepantes com as normas de funcionamento familiar, uma vez que, em geral, os pais não costumam castigar seus filhos quando o comportamento deles é adequado. A coerção pode ser mais efetiva do que a utilização apenas do diálogo, mas, apesar de resultar em um controle imediato do comportamento, esse controle será provisório e estará limitado à presença dos pais, se não houver diálogo e reflexão sobre o comportamento. 
Essas duas dimensões, combinadas, resultam em quatro estilos de socialização parental. O estilo autoritativo é caracterizado por uma alta aceitação e alta coerção. Os pais se comunicam bem com os filhos e são dispostos a aceitar seus argumentos, mas, junto com o diálogo, também praticam a coerção física e verbal e as privações. Os pais valorizam as decisões autônomas e a conformidade disciplinada, reconhecendo os interesses dos filhos, mas também seus próprios direitos especiais de adultos.

O estilo autoritário é caracterizado por baixa aceitação e alta coerção. Os pais usam do poder para exigir dos filhos certos comportamentos e têm uma baixa implicação afetiva, sendo pouco atentos e sensíveis às suas necessidades e vontades. Freqüentemente, esses pais não dão explicações a seus filhos, principalmente quando lhes dão ordens, e não estimulam as respostas verbais e o diálogo perante as transgressões nem costumam aceitar os argumentos dos filhos. A aceitação das normas é, portanto, externa (força da autoridade), não havendo internalização.

$\mathrm{O}$ estilo indulgente ou permissivodistingue-se pela alta aceitação e baixa coerção. Os pais se comunicam bem com os filhos e acreditam no diálogo para conseguir inibir comportamentos indesejáveis, mas não praticam a coerção; permitem que os filhos regulem suas próprias atividades, ajudando-os com explicações e levando-os a raciocinar sobre suas ações.

Por fim, o estilo negligente é marcado por baixa aceitação e baixa coerção. Os pais passam pouco afeto, coerção e limites para os filhos, caracterizando uma indiferença para com eles. Os pais negligentes permitem que os filhos se cuidem e se responsabilizem por si mesmos, porém sem ensinar-lhes responsabilidade, mas sim privando-os de afeto, apoio, atenção e cuidado. Quando os filhos se comportam adequadamente, os pais se mostram indiferentes e, quando transgridem as normas, não dialogam nem exercem práticas coercitivas.

Musitu e García (2001) também avaliaram a socialização parental a partir da percepção dos filhos. Avaliar os estilos dos pais a partir da percepção dos filhos adolescentes, além de ser atualmente uma prática utilizada por diversos pesquisadores (ver, por exemplo, Lamborn et al., 1991 e Steinberg et al., 1994), é também uma necessidade investigativa, apontada por autores como Turck e Miller (1983) como uma maneira de melhor entender a estrutura familiar dos adolescentes. Ademais, avaliar a percepção dos filhos acerca das práticas parentais de socialização é uma forma de considerar suas interpretações como fazendo parte do processo de socialização.

A opção por estudar a socialização parental através do modelo e da técnica desenvolvida por Musitu e García (2001) se deu pelo fato desses autores terem desenvolvido, na Espanha, um estudo que relacionava, dentre outros construtos, as práticas parentais e os estilos de socialização com os sistemas de valores.

Os valores sociais são fundamentais na organização dos sistemas de crenças dos indivíduos (Rokeach, 1979a). Eles servem como padrões ou critérios que orientam ações, escolhas, julgamentos, atitudes e explicações sociais (Rokeach, 1979b; Williams, 1979) e ocupam uma posição central na rede cognitiva que fundamenta a organização das pessoas em sociedades (Rokeach, 1968). Além disso, são amplamente compartilhados pelos grupos sociais (Maio \& Olson, 1998; Maio, Olson, Allen \& Bernard, 2001) e, portanto, são fatores importantes no processo de socialização. Entretanto, o conjunto de estudos sobre os valores é marcado pela diversidade de abordagens teóricas que orientam as pesquisas (Torres et al., 2001). Dentre as teorias, destacam-se a tipologia dos valores proposta por Rokeach (1973), a teoria dos tipos motivacionais de Schwartz (1992) e a teoria dos valores materialistas e pós-materialistas discutida por Inglehart (1977). Na Universidade Federal da Paraíba, o Grupo de Pesquisa em Comportamento Político vem desenvolvendo uma abordagem que considera os valores como construções sociais, estreitamente relacionadas ao comportamento político (Lima, 1997; Lima \& Camino, 1995; Pereira, Lima \& Camino, 1997; Torres, 1992). A partir dessas pesquisas, o Grupo da Paraíba mostrou que, nos estudantes, os valores se organizam em quatro sistemas: 'materialista', 'pós-materialista', 'religioso' e 'hedonista'; e que o sistema de valores 'pós-materialista' estaria ligado às atitudes democráticas (Pereira, Lima \& Camino, 2001).

Essa abordagem (Pereira, Camino \& da Costa, no preloa) se faz a partir de uma análise do papel que os valores desempenham na sociedade, através de um questionário que acessa os valores que idealmente deveriam guiar as sociedades. Pereira, Camino e da Costa (no prelo-b) têm proposto uma abordagem que procura integrar diversos níveis de análise dos sistemas de valores. No que se refere à relação entre a abordagem motivacional dos valores de Schwartz (1992) e a abordagem societal, Pereira et al. (no prelo-b) mostram que existe uma forte convergência entre a abordagem societal por eles empregada e os tipos motivacionais da teoria de Schwartz.

Na definição dos tipos motivacionais, Schwartz (1992) propõe um modelo que organiza essa estrutura de uma forma bidimensional. Uma dimensão, localizada no eixo horizontal, seria formada pela oposição entre a Abertura à mudança (compatibilidade entre os domínios motivacionais Auto-direção e Estimulação) e a Conservação (compatibilidade entre os domínios motivacionais Segurança, Tradição e Conformidade). Os princípios que estão em conflito nesta dimensão são, por um lado, a ênfase na independência e o favorecimento da mudança e, por outro lado, a submissão e a manutenção das práticas tradicionais e da estabilidade pessoal.

A segunda dimensão, localizada no eixo vertical, seria formada pela oposição entre a Auto-transcendência (compatibilidade entre os domínios motivacionais Universalismo e Benevolência) e a Auto-promoção (compatibilidade entre os domínios motivacionais Poder e Realização). Os conflitos nesta dimensão ocorrem entre a superação dos próprios interesses em função do bemestar dos outros em oposição à busca de sucesso e de poder. O domínio motivacional Hedonismo, por sua vez, possui elementos tanto da dimensão Abertura à mudança quanto da dimensão Auto-promoção. 
Assim, de acordo com Pereira et al. (no prelo-b), existiria relação entre o sistema 'materialista' e os valores de auto-promoção, entre o sistema 'hedonista' e a abertura à mudança, entre o sistema 'religioso' e os valores de conservação e, finalmente, entre o 'pós-materialista' e o tipo motivacional da auto-transcendência.

Considerando o exposto, a pesquisa empírica que será apresentada teve por objetivo principal verificar, a partir da percepção de adolescentes, a relação existente entre os valores ideais para uma sociedade e as práticas utilizadas pelos seus pais para guiar a socialização de seus filhos nessa sociedade.

Vale salientar que um estudo que permita estabelecer uma relação de causa e efeito poderia ser realizado através de uma pesquisa experimental ou longitudinal com medidas repetidas. Porém, a proposta do presente trabalho consiste apenas em realizar uma pesquisa de campo com delineamento correlacional. Este tipo de delineamento, apesar de não possibilitar afirmar que as práticas socializadoras promovem a construção de determinados valores, permite fazer algumas inferências causais, levando em consideração as perspectivas teóricas adotadas.

\section{Método}

\section{Participantes}

Participaram do estudo 2.004 pré-adolescentes e adolescentes, com idades variando entre 10 e 18 anos, de ambos os sexos, estudantes do ensino fundamental e médio de escolas públicas e privadas das cidades de João Pessoa e Campina Grande, na Paraíba.

Tabela 1

Distribuição da Amostra por Idade e Sexo

\begin{tabular}{l|c|c|c}
\hline Idade & Moça & Rapaz & Total \\
\hline 10 anos & 19 & 14 & 33 \\
11 anos & 73 & 79 & 152 \\
12 anos & 92 & 90 & 182 \\
13 anos & 138 & 116 & 254 \\
14 anos & 171 & 140 & 311 \\
15 anos & 187 & 144 & 331 \\
16 anos & 143 & 146 & 289 \\
17 anos & 136 & 125 & 261 \\
18 anos & 112 & 74 & 186 \\
Não especificaram & - & - & 5 \\
\hline & 1.071 & 928 & 2.004 \\
\hline
\end{tabular}

Tabela 2

Distribuição da Amostra por Cidade e Tipo de Escola

\begin{tabular}{l|c|c|c}
\hline Cidade & Pública & Privada & Total \\
\hline João Pessoa & 693 & 685 & 1.378 \\
Campina Grande & 299 & 327 & 626 \\
& 992 & 1.012 & 2.004 \\
\hline
\end{tabular}

\section{Instrumentos}

Utilizou-se a Escala de Socialização Parental na Adolescência (ESPA29) e o Questionário de Valores Psicossociais. A ESPA29, criada para avaliar os estilos de socialização parental através da percepção dos filhos, foi desenvolvida e validada na Espanha e Itália por Musitu e García (2001) e traduzida para o português por dois tradutores bilíngües. Após a tradução, realizou-se um estudopiloto com estudantes de uma escola pública de Campina Grande, com idades entre 11 e 13 anos. Esse instrumento permite que o sujeito avalie, separadamente, a atuação socializadora do pai e da mãe. Para cada um dos pais, é apresentado um conjunto de 29 situações que ocorrem na vida familiar. O sujeito deve avaliar a reação dos pais em função das seguintes expressões: demonstra-me carinho, não se preocupa comigo, fala comigo, tanto faz, reclama comigo, bate em mim e retira algo ou proíbe. As avaliações são feitas através da atribuição de pontuações que variam de 1 a 4 ( 1 é igual a nunca, 2 é igual a algumas vezes, 3 é igual a muitas vezes e 4 é igual a sempre), indicando a forma como os pais se comportam em cada uma das situações.

As expressões acima citadas representam as sete subescalas que compõem a escala, sendo que quatro delas comporiam a dimensão de 'aceitação' (afeto, indiferença, diálogo e displicência) e as outras três comporiam a dimensão de 'coerção' (coerção verbal, coerção física e privação). A pontuação da dimensão 'aceitação' seria obtida a partir da soma dos escores das quatro subescalas correspondentes a esta dimensão, sendo que a indiferença e a displicência se correlacionariam negativamente com a 'aceitação' (por isso, seus escores são revertidos para o cômputo da pontuação). A pontuação da dimensão 'coerção' seria obtida com a soma dos escores das três subescalas correspondentes.

O questionário de valores utilizado é uma adaptação do instrumento elaborado e validado nos estudos anteriormente citados. Os vinte e três valores que compõem esse instrumento são: lucro, riqueza, status, autoridade, realização profissional, responsabilidade, dedicação ao trabalho, competência, alegria, amor, auto-realização, conforto, fraternidade, liberdade, igualdade, justiça, salvação da alma, temor a Deus, religiosidade, uma vida excitante, sensualidade, prazer e sexualidade. Para cada valor, os sujeitos devem atribuir uma nota variando entre 1 e 5 , considerando a sua importância (1 é igual a sem importância, 2 é igual a pouco importante, 3 é igual a mais ou menos importante, 4 é igual a muito importante e 5 é igual a extremamente importante) para a construção de uma sociedade ideal para se viver. Posteriormente, os escores dos valores individuais são somados para compor as pontuações dos sistemas valorativos.

É importante destacar que, como a versão utilizada nos estudos realizados com estudantes universitários não continha os significados de cada valor, mas apenas apresentava aos sujeitos os valores em si, constatou-se a necessidade de uma definição desses valores, uma vez que a amostra do presente estudo seria constituída por sujeitos a partir de dez anos, que, acreditava-se, teriam dificuldades em entender determinados valores que não estivessem melhor explicados. 
Assim, pediu-se a 39 estudantes da sétima série de uma escola pública de Campina Grande, com idades variando entre 11 e 15 anos que definissem os 23 valores que compõem o questionário de valores. A partir dessas definições, deu-se significado aos valores, o que resultou na versão utilizada na presente pesquisa.

\section{Procedimento}

Os participantes responderam aos questionários individualmente, mas em situação coletiva, ou seja, em sala de aula. Após um breve explicação sobre os objetivos e o sigilo da pesquisa, bem como sobre o anonimato dos participantes, os alunos foram convidados voluntariamente a responder aos questionários. Em cada sala de aula, havia cerca de três aplicadores, previamente treinados. O número de recusas em responder ao questionário foi estimado em cerca de $3 \%$ da amostra total. A permissão para a aplicação dos instrumentos foi obtida previamente através do contato com os responsáveis pelas instituições de ensino onde os sujeitos estudavam.

\section{Resultados}

Para que se pudesse investigar a relação entre a percepção das práticas de socialização e os sistemas de valores dos adolescentes, era preciso confirmar as estruturas propostas pelos dois modelos teóricos adotados nesta pesquisa: o modelo de socialização parental proposto por Musitu e García (2001) e o modelo de valores proposto por Lima e Camino (1995) e Pereira et al. (2001).

Para avaliar como se encontra organizada a percepção dos filhos acerca das práticas de socialização dos pais, foram realizadas Análises dos Componentes Principais, com rotação varimax.
Diante da perspectiva teórica adotada, que limita a existência de duas dimensões subjacentes às práticas parentais, realizou-se, inicialmente, uma Análise dos Componentes Principais para cada um dos pais, limitando a existência de apenas dois fatores. Todavia, a estrutura fatorial apareceu totalmente confusa, misturando construtos que deveriam fazer parte da 'aceitação' com os da 'coerção' e vice-versa. Em virtude dessa confusão e levando-se em consideração os resultados encontrados por Aunola, Stattin e Nurmi (2000) e por Lamborn et al. (1991) sobre a existência de mais de duas dimensões relativas às práticas de socialização, optouse por realizar uma Análise dos Componentes Principais com rotação varimax para os fatores com eigenvalues maiores do que 1. Os resultados desta análise apontam para uma estrutura composta por três fatores - 'aceitação', 'coerção' e ‘displicência'-, como pode ser visto na Tabela 1.

Já para analisar a adequação da estrutura de valores proposta por Lima e Camino (1995) e Pereira et al. (2001), foi realizada uma MDS (Multidimensional Scaling Escalonamento Multidimensional), técnica que utiliza medidas de dissimilaridades, distâncias euclidianas, que podem ser consideradas análogas ao conceito de distância psicológica da Teoria de Campo de Kurt Lewin. Diferentemente da Análise Fatorial, a MDS proporciona um tipo de mapa mental que oferece uma interpretação em termos de dimensões, não de fatores subjacentes à forma de responder a um conjunto de itens.

Essa técnica apresenta dois indicadores de bondade de ajuste em relação ao número de dimensões assumidas: a Correlação Múltipla ao Quadrado (Root Square - RSQ) e o coeficiente stress. O primeiro índice refere-se à proporção de variância explicada pela solução proposta através da técnica. Varia de 0,00 a 1,00; quanto maior, mais apropriada

Tabela 3

Análise dos Componentes Principais da Percepção das Práticas de Socialização de Ambos os Pais

\begin{tabular}{|c|c|c|c|c|c|}
\hline & & Coerção & Aceitação & Displicência & alpha \\
\hline \multirow[t]{7}{*}{ Mãe } & Privação &, 756 & & & ,936 \\
\hline & Coerção física & ,691 & & & ,925 \\
\hline & Coerção verbal & ,646 & & &, 902 \\
\hline & Afeto & &, 792 & &, 945 \\
\hline & Diálogo & &, 680 & & ,918 \\
\hline & Displicência & & &, 746 &, 901 \\
\hline & Indiferença & & & ,761 & ,946 \\
\hline \multirow[t]{7}{*}{ Pai } & Privação &, 750 & & & ,918 \\
\hline & Coerção física & ,666 & & &, 912 \\
\hline & Coerção verbal &, 697 & & &, 878 \\
\hline & Afeto & &, 816 & &, 947 \\
\hline & Diálogo & & ,763 & & ,908 \\
\hline & Displicência & & & ,729 & ,893 \\
\hline & Indiferença & & & ,767 & ,906 \\
\hline \multicolumn{2}{|c|}{ Coeficiente alpha } &, 960 & ,961 &, 954 &, 957 \\
\hline \multicolumn{2}{|c|}{ Eigenvalue } & 3,55 & 2,85 & 1,70 & - \\
\hline \multicolumn{2}{|c|}{ Variância Explicada (58\%) } & $25 \%$ & $21 \%$ & $12 \%$ & - \\
\hline
\end{tabular}


será a representação obtida. Não existe um valor crítico para decidir sobre a adequação do modelo (Bisquera, 1989). $\mathrm{O}$ segundo indica o grau de ajustamento das variáveis às dimensões obtidas, que deve ser inferior a ,15 para que seja considerado adequado (Abelson, 1967).

Os resultados mostraram a formação de quatro agrupamentos, de modo que os valores status, riqueza, lucro e autoridade constituem o conjunto de valores 'materialistas'; os valores uma vida excitante, sensualidade, prazer e sexualidade formam os valores 'hedonistas'; os valores temor a Deus, religiosidade e salvação da alma formam o sistema de valores 'religiosos'; e os valores realização profissional, responsabilidade, dedicação ao trabalho, competência (bemestar profissional), alegria, amor, auto-realização, conforto (bem-estar individual), fraternidade, liberdade, igualdade, justiça social (bem-estar social) formam o grande conjunto de valores 'pós-materialistas', como se pode observar na Figura 1. Em função das análises anteriores, cada conjunto foi somado e os coeficientes alpha de fidedignidade foram calculados para cada uma das escalas assim formadas: valores 'materialistas' $(\alpha=.75)$, 'hedonistas' $(\alpha=.81)$, 'religio$\operatorname{sos}^{\prime}(\alpha=.72)$ e ) 'pós-materialistas' $(\alpha=.88)$.

Para verificar as relações entre a percepção das práticas de socialização e a adesão aos sistemas de valores dos adolescentes, foram realizadas Regressões Múltiplas, utilizando como variáveis critério cada um dos sistemas de valores dos adolescentes. Já as variáveis antecedentes foram as três dimensões das práticas parentais.

No que se refere aos valores 'religiosos', os resultados mostraram que a prática parental 'aceitação' se relaciona positivamente com esses valores, enquanto a 'displicência' relaciona-se negativamente.

Figura 1. Organização dimensional da estrutura valorativa dos adolescentes (MDS). ${ }^{2}$

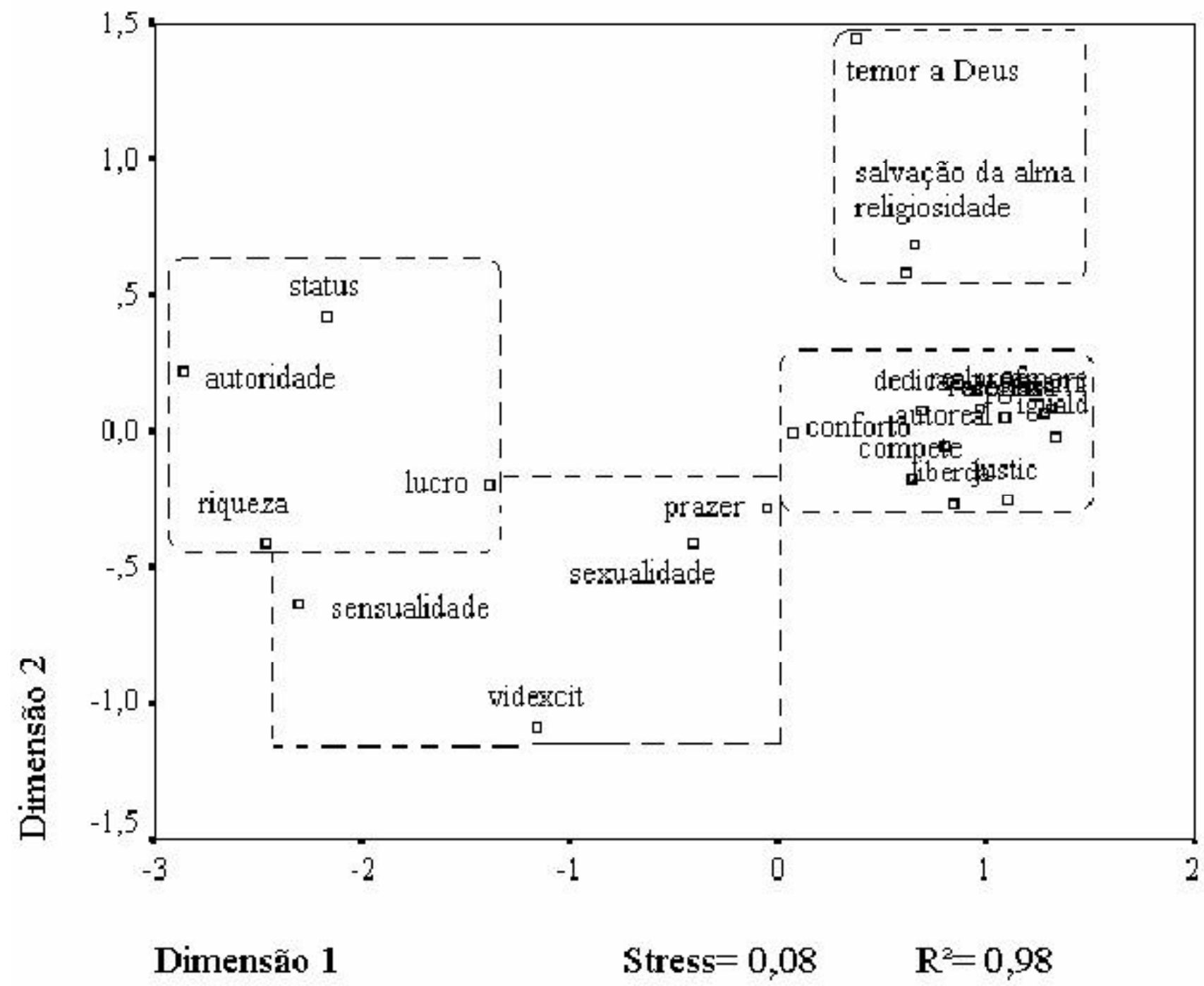

\footnotetext{
${ }^{2}$ Os valores que compõem a "mancha” localizada no lado direito da figura são: realização profissional, responsabilidade, dedicação ao trabalho, competência, alegria, amor, auto-realização, conforto, fraternidade, liberdade, igualdade e justiça social.
} 
Moraes, R., Camino, C., Costa, L. B., Camino, L. \& Cruz, L. (2007). Socialização Parental e Valores: Um Estudo com Adolescentes.

Tabela 4

Relações entre a Percepção das Práticas e os Valores Religiosos (Regressão Múltipla)

\begin{tabular}{l|c|c|c}
\hline & beta & $t$ & $p$ \\
\hline Aceitação &, 062 & 2,304 &, 021 \\
\hline Coerção &, 003 &, 122 & n.s. \\
\hline Displicência &,- 087 & $-3,276$ &, 001 \\
\hline $\begin{array}{l}\text { Coeficiente de Regressão } \\
\text { Múltipla } \\
\text { Variância Explicada }\end{array}$ & \multicolumn{3}{|c}{$R=, 115$} \\
\hline Teste Estatístico & $R^{2}=, 013 \quad R^{2}$ ajustado=,012 \\
\hline
\end{tabular}

Quanto aos valores 'materialistas', pode-se observar que as práticas parentais ‘aceitação’ e ‘displicência' (maior aceitação e maior displicência) estão relacionadas com a alta adesão a esse sistema valorativo.

Tabela 5

Relações entre a Percepção das Práticas e os Valores Materialistas (Regressão Múltipla)

\begin{tabular}{l|c|c|c}
\hline & beta & $T$ & $p$ \\
\hline Aceitação &, 104 & 3,842 &, 000 \\
\hline Coerção &, 046 & 1,659 & n.s. \\
\hline Displicência &, 055 & 2,055 &, 040 \\
\hline $\begin{array}{l}\text { Coeficiente de Regressão } \\
\text { Múltipla } \\
\text { Variância Explicada }\end{array}$ & \multicolumn{3}{|c}{$\begin{array}{c}R=, 108 \\
R^{2} \text { ajustado }=, 010\end{array}$} \\
\hline Teste Estatístico & \multicolumn{3}{|c}{$F=8,345 \quad p<, 001$} \\
\hline
\end{tabular}

No que se refere aos valores 'pós-materialistas', houve uma relação de todas as variáveis antecedentes com esse sistema: quanto maior a 'aceitação', maior a adesão a esses valores e quanto maior a 'coerção' e a 'displicência', menor a adesão.

Tabela 6

Relações entre a Percepção das Práticas e os Valores Pós-Materialistas (Regressão Múltipla)

\begin{tabular}{l|c|c|c}
\hline & beta & $t$ & $p$ \\
\hline Aceitação &, 139 & 5,054 &, 000 \\
\hline Coerção &,- 106 & $-4,060$ &, OOO \\
\hline Displicência &,- 189 & $-7,092$ & ,000 \\
\hline $\begin{array}{l}\text { Coeficiente de Regressão } \\
\text { Múltipla } \\
\text { Variância Explicada }\end{array}$ & \multicolumn{3}{|c}{$R=, 281$} \\
$R^{2}=, 079$ & $R^{2}$ ajustado= ,077 \\
\hline Teste Estatístico & \multicolumn{3}{|c}{$F=39,093 \quad p<, 001$} \\
\hline
\end{tabular}

Não foram encontradas relações significativas entre as práticas de socialização e os valores 'hedonistas'.

\section{Discussão}

Os resultados indicaram a existência não de dois, mas de três fatores ou dimensões, denominadas de 'aceitação', 'coerção’ e ‘displicência’. Teoricamente, Musitu e García (2001) pressupõem que a indiferença e a displicência, variáveis que neste trabalho formam o fator 'displicência', fariam parte, através de uma correlação negativa, do fator 'aceitação’. Ou seja, a ‘aceitação’ seria caracterizada não só pela presença de afeto e diálogo, mas também pela ausência da indiferença e da displicência. No entanto, parece haver, para os adolescentes paraibanos, uma clara diferenciação entre dar afeto e dialogar - atitudes que refletem relações de maior proximidade - e a ausência de displicência e indiferença formas de agir que refletem uma falta de atenção dos pais para com seus filhos.

Quais as razões para esses resultados? Há vários caminhos para explicá-los. Primeiramente, pode-se falar sobre possíveis variações entre diferentes grupos culturais. Estudos (ver Gorman, 1998; Lin \& Fu, 1990; Steinberg et al., 1994) indicam que há diferenças nas formas de agir dos pais em função das diferenças culturais. Desta forma, como a escala usada na presente pesquisa havia sido utilizada apenas para investigar a socialização familiar em culturas européias (Espanha e Itália), pode-se atribuir a existência de uma terceira dimensão às especificidades da cultura brasileira, sobretudo do nordeste do país.

Ademais, outras pesquisas têm demonstrado a existência de mais de duas dimensões relativas aos estilos parentais de socialização. Smetana (1995) defende que os estilos parentais podem envolver outros fatores além da aceitação e controle parental. Steinberg et al. (1994), por sua vez, vêm, há algum tempo, propondo que, pelo menos em relação ao estilo autoritativo, existem, na sua definição, não apenas dois, mas três fatores ou dimensões: responsividade, exigência e autonomia psicológica (característica que reflete a extensão com que os pais empregam a disciplina democrática e encorajam o adolescente a expressar sua individualidade). Lamborn et al. (1991), investigando a relação entre os estilos parentais e padrões de competência e ajustamento na adolescência, também encontraram a existência empírica dos três fatores citados. Mas, como o interesse maior desses autores era testar o "esqueleto conceitual” de Maccoby e Martin (1983) a partir dos fatores responsividade e exigência, eles optaram por não levar em conta a autonomia psicológica na definição dos estilos parentais.

No entanto, os estudos de Steinberg continuaram a sugerir que, na adolescência, o estilo autoritativo é melhor definido a partir das três dimensões: aceitação, controle e autonomia psicológica (Steinberg, Dornbusch \& Brown, 1992), mas complementaram dizendo que a autonomia psicológica não é um fator importante para diferenciá-lo dos outros estilos - autoritário, permissivo e negligente (Steinberg et al.,1994). Sendo assim, essa dimensão não tem sido usada nas pesquisas realizadas por Steinberg e seus colegas (Lamborn et al., 1991; Steinberg et al., 1994) para definir o estilo autoritativo, quando este tem sido comparado aos outros estilos. 
Ao contrário desses autores, Mantzicopoulos e Oh-Hwang (1998) desenvolveram um estudo em que relacionaram os estilos parentais com a maturidade psicossocial de adolescentes coreanos e americanos, considerando, na definição do estilo autoritativo, a elevada autonomia psicológica associada a altos índices de aceitação e controle. Esses autores também criaram um estilo "misto", definido a partir da combinação de altos índices de aceitação e coerção e baixo índice de autonomia psicológica. Desta forma, o que esses autores mostram de mais inovador é o fato de considerarem, na definição de alguns dos estilos, a autonomia psicológica e, também, o fato de encontrarem diferenças entre o estilo autoritativo e o "misto" na associação com o grau de maturidade psicossocial. Isto indica que considerar essa dimensão na definição do estilo autoritativo causa diferenças que repercutem nos fatores investigados.

Diante dessas pesquisas empíricas, convém questionar a forma como os estilos de socialização têm sido definidos. A maioria dos autores continua a optar por definir os estilos através de duas dimensões. Porém, como defendem Lyra e Moura (2000), não se pode simplesmente continuar realizando pesquisas aplicadas, cujos dados empíricos são acoplados a explicações teóricas já existentes na literatura e raramente analisadas de forma crítica. É preciso reconceitualizar os pressupostos teóricos quando necessário e relacioná-los a uma metodologia adequada para a investigação dos mesmos.

Neste sentido, parece que este estudo traz uma contribuição teórica ao tema. Assim como há aqueles autores que defendem a existência de uma outra dimensão na definição do estilo autoritativo, parece oportuno, diante das evidências empíricas encontradas, trazer à tona um novo debate: a existência de uma nova dimensão - 'displicência' - que melhor definiria, pelo menos, o estilo negligente. Mas por que esse estilo? O estilo negligente é definido pelos teóricos pela ausência de aceitação e controle. No entanto, como já foi dito, os adolescentes paraibanos diferenciaram claramente a aceitação da displicência, mostrando que o fato de não haver indiferença ou displicência não é o mesmo que haver afeto e diálogo. Da mesma forma, a falta de afetividade não supõe a indiferença (o estilo autoritário é marcado pela ausência de afetividade, porém o forte controle exercido pelos pais descarta a possibilidade de displicência por parte dos mesmos). Assim, esses fatores demarcam territórios diferentes das práticas de socialização. Territórios que, diante de uma reflexão teórica, parecem fazer mais sentido em relação ao estilo negligente. O próprio sentido da palavra negligenciar (descuidar-se, tratar com desleixo, insensibilidade) mostra a relação desse fator com o estilo em questão. Além disso, Aunola et al. (2000) afirmam ser típico desse estilo uma completa falta de envolvimento dos pais em relação aos filhos.

Enfim, de uma maneira geral, os resultados da presente pesquisa mostram que a percepção subjetiva dos adolescentes acerca das suas relações com seus pais não corresponde ao sugerido através de um modelo teórico que tem sido amplamente divulgado desde a década de 70 - através da tipologia proposta por Baumrind (1971); consolidado nos anos 80 - por meio do trabalho de Maccoby e Martin (1983); e comprovado na década de 90, através de diversos estudos realizados com adolescentes. Apesar disso, o que parece é que vários dos estudos realizados na década de 90 acabaram, na verdade, por tentar se adequar ao modelo proposto por Baumrind (1991) e ao esquema bidimensional de Maccoby e Martin (1983). É o caso de Shucksmith et al. (1995), que mesmo identificando várias dimensões distintas que compõem a relação entre pais e adolescentes britânicos, procuraram adequá-las num agrupamento de aceitação e controle.

É importante lembrar também que, inicialmente, os estudos sobre as práticas de socialização investigavam, sobretudo, as relações familiares entre crianças e pais. A partir do final da década de 80 (ver Dornbusch et al., 1987), esses estudos procuraram ampliar o modelo para a população de adolescentes. Todavia, é de se esperar que relações entre crianças e seus pais sejam diferenciadas daquelas estabelecidas pelos pais com os adolescentes. As crianças necessitam de mais cuidados e são quase que totalmente dependentes dos pais em termos das suas necessidades fundamentais, o que concorre para o fato de não se falar, em relação a elas, de autonomia psicológica, por exemplo. Da mesma forma, seria mais difícil conceber uma forma de atuação (se é que pode ser denominada assim) baseada na 'displicência' no que diz respeito às crianças. Enfim, os resultados empíricos aqui encontrados apontam para a necessidade de maiores reflexões teóricas sobre o tema das práticas de socialização familiar em uma população de adolescentes.

Quanto aos valores, a adequabilidade do modelo estrutural proposto pelo Grupo de Pesquisa em Comportamento Político foi comprovada para os adolescentes através do procedimento de escalonamento multidimensional. Assim, os adolescentes podem ser considerados como um segmento social não tão distinto dos universitários.

Por fim, verificou-se a relação entre cada uma das dimensões - 'aceitação', 'coerção' e 'displicência' - e os sistemas de valores dos adolescentes. Em relação aos valores 'pós-materialistas', encontrou-se uma relação positiva entre a 'aceitação' e esses valores, corroborando os resultados encontrados por Musitu e García (2001), que revelaram que adolescentes provenientes de lares onde há uma alta 'aceitação' obtêm maiores pontuações do que aqueles de lares onde predomina uma baixa aceitação, em relação aos valores do universalismo e benevolência. Esses valores assemelham-se aos valores 'pós-materialistas' da tipologia aqui adotada.

Ainda no que se refere aos valores 'pós-materialistas', foram observadas relações negativas entre a 'coerção' e a 'displicência' e esses valores. A respeito da 'coerção', podese considerar que os resultados encontrados nos estudos de Camino et al. (2003) e Hoffman e Saltzstein (1967) foram aqui confirmados, já que esses autores observaram uma ação negativa da coerção sobre a descentração sócio-moral, supostamente necessária ao desenvolvimento de valores como igualdade e justiça social. O fato da 'displicência' também 
estabelecer uma relação negativa com esses valores parece mostrar ser difícil para os adolescentes pensar em termos sociais mais amplos quando a base das relações familiares é a indiferença. Essas relações são, na verdade, caracterizadas por uma falta de socialização e engajamento dos pais, fatores que não favoreceriam a descentralização dos adolescentes.

Em adição, foram encontradas relações positivas entre a 'aceitação' e a 'displicência' e o sistema 'materialista'. A este respeito, pode-se supor que, sendo a adolescência uma fase de insegurança, a 'displicência' acentuaria esta insegurança e, desse modo, aumentaria o desejo dos adolescentes por um estilo de vida mais seguro. A 'aceitação', por sua vez, não seria suficiente para eliminar a insegurança. Também se pode supor que pais displicentes são, muitas vezes, pais que trabalham demais, preocupando-se, sobretudo, com questões financeiras da família ou com os problemas do trabalho, revelando uma orientação predominantemente voltada para a aquisição de riqueza e status. Neste sentido, os valores dos filhos refletiriam não apenas as práticas de socialização dos pais, mas também os valores dos próprios pais, o que poderia ser explicado por teorias sobre modelação e aprendizagem observacional (Bandura, 1969; Bandura \& McDonald, 1963).

Somando-se a essas constatações, foram verificadas: uma relação positiva entre a 'aceitação' e os valores do sistema 'religioso' e uma relação negativa entre a 'displicência' e esse sistema. Em relação à 'aceitação', Musitu e García (2001) obtiveram resultados semelhantes, uma vez que encontraram uma relação positiva entre essa prática de socialização e os tipos motivacionais tradição e conformidade. Esses tipos motivacionais compõem os valores de conservação (Schwartz, 1992), que, por sua vez, apresentam semelhança empírica com o sistema 'religioso' (Pereira et al., 2001). Com respeito ao uso da 'displicência', é fácil supor que, quanto maior a ausência de atenção dos pais, menor a importância atribuída à religiosidade, uma vez que atitudes religiosas dependem de ensinamentos específicos.

Finalmente, acredita-se que o fato de não ter havido nenhuma relação entre as práticas de socialização e os valores do sistema 'hedonista' indica que esses valores são, muitas vezes, deixados pelos pais para serem abordados por outros agentes de socialização, como a escola, sendo desenvolvidos também na relação com os amigos e através da mídia, cada vez mais apontada como forte agente de socialização (Grusec, 2002).

\section{Conclusões Finais}

A maioria dos estudos sobre socialização parental na adolescência tem considerado apenas a percepção dos adolescentes, e não a dos pais. No entanto, Paulson e Sputa (1996) compararam a percepção de pais e mães de adolescentes americanos com a percepção dos filhos e encontraram que a percepção de ambos os pais acerca do seu grau de responsividade e exigência é mais elevada do que a percepção dos filhos. Em outros estudos, como o de Grusec e Goodnow (1994), foi acentuada a importância dos processos de caráter mais cognitivo, como é o caso da percepção das mensagens parentais, na construção e aquisição de valores. Por fim, outros estudos compararam se os valores dos filhos e dos pais coincidem, mostrando que não. Em sua maioria, os resultados dessas pesquisas indicaram que os valores dos adolescentes se parecem com aqueles que os filhos crêem que seus pais têm (Molpeceres, Llinares \& Musitu, 2001). Desta forma, parece válido investigar, em pesquisas futuras acerca do processo de socialização de valores, se a percepção dos filhos acerca das formas de atuação dos pais corresponde às formas como os pais acreditam que atuam ou percebem que atuam.

Além disso, é válido salientar que, embora os pais sejam considerados importantes agentes de socialização, reconhece-se, atualmente, que o impacto dos pais nos seus filhos não é tão direto, simples e claro como anteriormente se imaginava (Collins, Maccoby, Steinberg, Hetherington \& Bornstein, 2000). Os resultados do presente estudo, por exemplo, indicaram que uma única dimensão, por si só, qualquer que seja ela, não permite precisar a magnitude da importância da socialização parental no processo de formação de valores; a complexidade de tal fenômeno aponta para a necessidade de abordá-lo de uma perspectiva multidimensional. Neste sentido, parecem ser promissoras as abordagens sistêmicas, como a de Sameroff (1983, citado por Parke, Ornstein, Rieser \& Zahn-Waxler, 1994), que propõe que as pesquisas sobre a família devem utilizar um paradigma que integre mini-teorias, envolvendo aspectos emocionais, biológicos, sociais e cognitivos.

\section{Referências}

Abelson, R. P. (1967). A technique and a model of multidimensional attitude scaling. In M. Fishbein (Ed.), Readings in attitude: Theory and measurement (pp. 349-356). New York: John Wiley \& Sons.

Alvaro, J. L., \& Garrido, A. (2003). Orientaciones conceptuales: entre el individuo e la sociedad. In J. L. Alvaro (Ed.), Fundamentos sociales del comportamiento humano (pp. 15-43). Barcelona, España: UOC.

Aronfreed, J. (1976). Moral development from the standpoint of a general psychological theory. In T. Lickona (Ed.), Moral development and behavior: Theory, research and social issues (pp. 54-69). New York: Holt, Rinehart and Winston.

Assmar, E. M. L., Ferreira, M. C., Novaes, H., \& Tomaz, M. (2000). Premissas histórico-socioculturais sobre a família brasileira em função do sexo e da idade. Psicologia: Reflexão e Crítica, 13, 89-96.

Aunola, K., Stattin, H., \& Nurmi, J-E. (2000). Parenting styles and adolescents' achievement strategies. Journal of Adolescence, 23, 205-222.

Bandura, A. (1969). Social learning of moral judgment. Journal of Personality and Social Psychology, 11, 275-279.

Bandura, A., \& McDonald, F. J. (1963). Influence of social reinforcement and the behavior of models in shaping children's moral judgments. Journal of Abnormal and Social Psychology, 67, 274-281.

Baumrind, D. (1971). Current patterns of parental authority. Developmental Psychology, 4, 1-101.

Baumrind, D. (1991). The influence of parenting style on adolescent competence and substance use. Journal of Early Adolescence, 11, 56-95. 
Baumrind, D. (1996). The discipline controversy revisited. Family Relations, 45, 405-414.

Bisquera, R. (1989). Introducción conceptual al análisis multivariable: Un enfoque con los paquetes estadísticos SPSS-X, BMDP, LISREL y SPAD. Barcelona, España: PPU.

Camino, C., Camino, L., \& Moraes, R. (2003). Moralidade e socialização: Estudos empíricos sobre práticas maternas de controle social e o julgamento moral. Psicologia: Reflexão e Crítica, 16, 41-61.

Collins, W. A., Maccoby, E., Steinberg, L., Hetherington, E. M., \& Bornstein, M. (2000). Contemporary research on parenting: The case for nature or nurture. American Psychologist, 55, 218 232.

Costa, F. T., Teixeira, M., \& Gomes, W. B. (2000). Responsividade e exigência: Duas escalas para avaliar estilos parentais. Psicologia: Reflexão e Crítica, 13, 465-473.

Darling, N., \& Steinberg, L. (1993). Parenting style as context: An integrative model. Psychological Bulletin, 113, 487-496.

Dornbusch, S. M., Ritter, P. L., Leiderman, P. H., Roberts, D. F., \& Fraleigh, M. J. (1987). The relation of parenting style to adolescent school performance. Child development, 58, 12441257.

Eisenberg, N., \& Mussen, P. H. (1989). The roots of prosocial behavior in children. Cambridge, MA: Cambridge University Press.

Gorman, J. C. (1998). Parenting attitudes and practices of immigrant chinese mothers of adolescents. Family Relations, 47, 73-80.

Grusec, J. E. (2002). Parental socialization and children's acquisition of values. In M. Bornstein (Series Ed.), Handbook of parenting: Vol. 5. Practical issues in parenting (pp. 143-168). Mahwah, NJ: Lawrence Erlbaum.

Grusec, J. E., \& Goodnow, J. J. (1994). Impact of parental discipline methods on the child's internalization of values: A reconceptualization of current points of view. Developmental Psychology, 30, 4-19.

Hoffman, M. L. (1970). Moral development. In P. H. Mussen (Series Ed.), Handbook of child Psychology: Vol. 2. Infancy and Developmental Psychobiology (pp. 261-354). New York: Wiley.

Hoffman, M. L., \& Saltzstein, H. (1967). Parent discipline and the child's moral development. Journal of Personality and Social Psychology, 5, 45-57.

Inglehart, R. (1977). The silent revolution. Princeton, NJ: University Press.

Kuczynski, L., \& Grusec, J. E. (1997). Future directions for a theory of parental socialization. In J. E. Grusec \& L. Kuczynski (Eds.), Parenting and the internalization of values: A Handbook of contemporary theory (pp. 399-414). New York: Wiley.

Lamborn, S. D., Mounts, N. S., Steinberg, L., \& Dornbusch, S. M. (1991). Patterns of competence and adjustment among adolescents from authoritative, authoritarian, indulgent, and neglectful families. Child Development, 62, 1049-1065.

Lima M. E. (1997). Valores, participação política, atitudes face a democracia e ao autoritarismo: Uma análise da socialização política dos universitários da Paraíba. Dissertação de Mestrado nãopublicada, Curso de Pós-Graduação em Psicologia Social, Universidade Federal da Paraíba, João Pessoa, PB.

Lima, M.E., \& Camino, L. (1995). A política na vida de estudantes universitários: Uma análise em termos de espaço político e de valores. In M. J. Lima Silva (Ed.), Iniciados (pp. 13-36). João Pessoa, PB: Editora da Universidade Federal da Paraíba.
Lin, C. C., \& Fu, V. R. (1990). A comparison of child-rearing practices among chinese, immigrant chinese, and caucasianamerican parents. Child Development, 61, 429-433.

Lyra, M., \& Moura, M. L. S. (2000). Desenvolvimento na interação social e no contexto histórico-cultural: Adequação entre perspectiva teórica e metodológica. Psicologia: Reflexão e Crítica, 13, 217-222.

Maccoby, E. (1994). The role of parents in the socialization of children: An historical overview. In R. D. Parke, P. A. Ornstein, J. J. Rieser \& C. Zahn-Waxler (Eds.), A century of Developmental Psychology (pp. 589-615). Washington, DC: American Psychological Association.

Maccoby, E., \& Martin, J. (1983). Socialization in the context of the family: Parent-child interaction. In P. H. Mussen (Series Ed.) \& E. M. Hetherington (Vol. Ed.), Handbook of child Psychology: Vol. 4. Socialization, personality and social development (4th ed., pp. 1-101). New York: John Wiley \& Sons.

Maio, G. R., \& Olson, J. M. (1998). Values as truisms: Evidence and implications. Journal of Personality and Social Psychology, 74, $294-311$.

Maio, G. R., Olson, J. M., Allen, L., \& Bernard, M. (2001). Addressing discrepancies between values and behavior: The motivating effect of reasons. Journal of Experimental Social Psychology, 37, 104-117.

Mantzicopoulos, P. Y., \& Oh-Hwang, Y. (1998). The relationship of psychosocial maturity to parenting quality and intellectual ability for american and korean adolescents. Contemporary Educational Psychology, 23, 195-206.

Molpeceres, M., Llinares, L., \& Musitu, G. (2001). Internalización de valores sociales y estrategias educativas parentales. In M. Ros \& V. Gouveia (Eds.), Psicología social de los valores humanos. Desarrollos teóricos, metodológicos y aplicados (pp. 197-218). Madrid, España: Biblioteca Nueva.

Musitu, G., \& García, F. (2001). Escala de socialización parental en la adolescencia. Madrid, España: TEA.

Parke, R. D., Ornstein, P. A., Rieser, J. J., \& Zahn-Waxler, C. (1994). The past as prologue: An overview of a century of Developmental Psychology. In R. D. Parke, P. A. Ornstein, J. J. Rieser \& C. ZahnWaxler (Eds.), A century of Developmental Psychology (pp. 1-70). Washington, DC: American Psychological Association.

Paulson, S. E., \& Sputa, C. L. (1996). Patterns of parenting during adolescence: Perceptions of adolescents and parents. Adolescence, 31, 370-381.

Pereira, C. R., Lima, M. E., \& Camino, L. (1997). A prática política: Uma análise psicossociológica em termos de valores e inserção social. In M. J. L. Silva (Ed.), Iniciados (pp. 199-235). João Pessoa, PB: Editora Universitária da Universidade Federal da Paraíba.

Pereira, C. R., Lima, M. E., \& Camino, L. (2001). Sistemas de valores e atitudes democráticas de estudantes universitários de João Pessoa. Psicologia: Reflexão e Crítica, 14, 177-190.

Pereira, C., Camino, L., \& da Costa J. B. (no prelo-a). Análise fatorial confirmatória do Questionário de Valores Psicossociais - QVP24. Estudos de Psicologia.

Pereira, C., Camino, L., \& da Costa J. B. (no prelo-b). Um estudo sobre a integração dos níveis de análise dos sistemas de valores. Psicologia: Reflexão e Crítica.

Piaget, J. (1932). Le jugement moral chez l'enfant. Paris: Alcan.

Ribeiro, I., \& Ribeiro, A. C. T. (1994). Família e desafios na sociedade brasileira: Valores como um ângulo de análise. Rio de Janeiro, RJ: Centro João XXIII. 
Moraes, R., Camino, C., Costa, L. B., Camino, L. \& Cruz, L. (2007). Socialização Parental e Valores: Um Estudo com Adolescentes.

Rokeach, M. (1968). Beliefs, attitudes and values: A theory of organization and change. San Francisco, CA: Jossey-Bass.

Rokeach, M. (1973). The nature of human values. New York: Free Press.

Rokeach, M. (1979a) Introduction. In M. Rokeach (Ed.), Understanding human values: Individual and societal (pp. 1-11). New York: Free Press.

Rokeach, M. (1979b). The two-value model of political ideology and British politics. In M. Rokeach (Ed.), Understanding human values: Individual and societal (pp. 192-196). New York: Free Press.

Schwartz, S. H. (1992). Universals in the content and structure of values: Theoretical advances and empirical tests in 20 countries. In M. Zanna (Ed.), Advances in Experimental Social Psychology (pp. 1-65). Orlando, FL: Academic Press.

Shucksmith, J., Hendry, L. B., \& Glendinning, A. (1995). Models of parenting: Implications for adolescent well-being within differents types of family contexts. Journal of Adolescence, 18 , 253-270.

Smetana, J. G. (1995). Parenting styles and conceptions of parental authority during adolescence. Child Development, 66, 299-315.

Steinberg, L., \& Morris, A. S. (2001). Adolescent development. Annual Review of Psychology, 52, 83-110.

Steinberg, L., Dornbusch, S. M., \& Brown, B. B. (1992). Ethnic differences in adolescent achievement: An ecological perspective. American Psychologist, 47, 723-729.
Steinberg, L., Lamborn, S., Darling, N., Mounts, N. S., \& Dornbusch, S. M. (1994). Over-time changes in adjustment and competence among adolescents from authoritative, authoritarian, indulgent, and neglectful families. Child development, 65, 754-770.

Torres, A. R. (1992). Uma análise psicossocial da identificação partidária dos estudantes da UFPB nas eleições de 1988, 1989 e 1990. Dissertação de Mestrado não-publicada, Curso de Pós-Graduação em Psicologia Social, Universidade Federal da Paraíba, João Pessoa, PB.

Torres, A. R. R., Pereira, C., Guimarães, J., Albernaz, M., Vieira, S., \& Barros, T. (2001). Valores e Psicologia Social: Modelos de análise. Estudos, 28, 539-559.

Turck, M. A., \& Miller, G. R. (1983, August). Adolescent perceptions of parental persuasive message strategies. Journal of Marriage and the Family, 543-552.

Williams, R. M. (1979). Change and stability in values and value systems: A sociological perspective. In M. Rokeach (Ed.), Understanding human values: Individual and societal (pp. 15-46). New York: Free Press. 